\title{
Pre-treatment with Curcumin Enhances Plasma Concentrations of Losartan and Its Metabolite EXP3174 in Rats
}

\author{
An-Chang Liu, ${ }^{a, b}$ Li-Xia Zhao, ${ }^{a, b}$ Jie Xing, ${ }^{a}$ Tian Liu, ${ }^{a}$ Fu-Ying Du, ${ }^{a}$ and Hong-Xiang Lou ${ }^{*, a}$ \\ ${ }^{a}$ School of Pharmaceutical Sciences, Shandong University; West Wenhua Road 44, Jinan 250012, P.R. China: and \\ ${ }^{b}$ Qilu Hospital of Shandong University; West Wenhua Road 107, Jinan 250012, P. R. China.
}

Received July 23, 2011; accepted November 22, 2011; published online November 25, 2011

\begin{abstract}
The study was carried out in the Wistar rats to investigate the effect of curcumin pre-treatment on the pharmacokinetics of the hypertension-treating drug losartan and its metabolite EXP3174 following single oral administration. In the treatment group, rats were gavaged with losartan $10 \mathrm{mg} / \mathrm{kg}$ after repeat oral doses of curcumin $(100 \mathrm{mg} / \mathrm{kg}$, for $7 \mathrm{~d})$, while rats in the control group were administrated only with the same dose losartan. The results showed that curcumin significantly increased the plasma concentrations of losartan and its metabolite EXP3174. The present study implicated the existence of herb-drug interaction between curcumin and losartan, and further evaluation of the possible interaction during curcumin administration needs to be considered.
\end{abstract}

Key words losartan; curcumin; interaction

Losartan, a selective non-peptide angiotensin receptor antagonist, is an alternative of antihypertensive agents of angiotensin converting enzyme inhibitors (ACE-I) used in treating hypertension and heart failure. In recent years, the discovery of its antioxidative activity has enhanced the protection of cardiovascular injury and improved the treatment of hypertension. ${ }^{1-4)}$ Researches have showed that losartan-antioxidant hybrid may be more useful than losartan alone or controlling hypertension and preventing hypertension-induced cardiovascular damage. ${ }^{5)}$

Curcumin (Fig. 1), a polyphenol extracted from the rhizomes of turmeric (Curcuma longa L.), is widely used as a food coloring agent and spice in many countries. Interests in this dietary polyphenol have grown in recent years due to its pharmacological effects. Curcumin is known for its anti-carcinogenicity, ${ }^{6}$ ) ability to trigger anti-inflammatory responses $^{7,8)}$ and antioxidative bioactivity. ${ }^{9},{ }^{10)}$ On this basis, Phase I clinical trials of curcumin have been initiated in the United Kingdom $^{11)}$ and Taiwan ${ }^{12)}$ and also Phase II trials in the United states. ${ }^{13)}$ However, the safety concern of curcumin used as a food additive to the drugs is less studied. Research has suggested that it was imperative to conduct evaluation of curcumin-drug interactions to provide a better understanding of the effects of curcumin on pharmacokinetics of drugs. ${ }^{14)}$ The European Commission has requested related departments to reevaluate the safety of curcumin (E 100) when used as a food coloring substance. Without a doubt, the safety of curcumin use has begun to draw more and more attention. ${ }^{15)}$

Curcumin is often used in common dietary and may be considered as potential therapeutic agent for cardiovascular disease in recent years, ${ }^{16,17)}$ which possible result in curcumin being taken concomitantly with losartan as a combination therapy to treat or prevent hypertension and related cardiovascular damage. As known, in the clinic, the effect of herb<smiles>COc1cc(/C=C/C(=O)CC(=O)/C=C/c2ccc(O)c(OC)c2)ccc1O</smiles>

Fig. 1. Chemical Structure of Curcumin on drug maybe easy to be found by the exaggerative pharmacodynamic effect. But slightly changing of pharmacokinetics of drugs, which can not be obviously observed in pharmacodynamic effects, may also increase the risk of side effects. The present study focused on whether curcumin affects the pharmacokinetics of losartan in order to avoid the potential adverse drug reaction of losartan in clinical therapy.

\section{MATERIALS AND METHODS}

Chemicals and Agents Losartan was supplied by Dawnrays Pharmaceutical (Holding) Limited (Suzhou, China), EXP3174 was purchased from International Laboratory Limited (San Bruno, CA, U.S.A.) and irbesartan was obtained from National Institutes for Food and Drug Control (Beijing, China). Curcuma longa L. was purchased from Jianlian traditional Chinese medicine store. Acetonitrile, ammonium acetate and formic acid (HPLC grade) were supplied by Tedia Co., Inc. (Fairfield, OH, U.S.A.). Deionized water was obtained from a Millipore Milli-Q Gradient Water Purification System (Molsheim, France). Chemical structures of losartan and EXP3174 are shown in Fig. 2.

Animals Specific-pathogen-free grade healthy Wistar rats (180-220g, 7 males and 7 females) were obtained from Beijing Medical Laboratory Animal Center (Beijing, P.R. China). Rats were kept in an environmentally controlled breeding room (temperature $25 \pm 2{ }^{\circ} \mathrm{C}$, humidity $60 \pm 5 \%, 12 \mathrm{~h}$ dark/light cycle) for 1 week before the experiment. They were fed a soy-free custom diet (Beijing Medical Laboratory Animal Center, Beijing, P.R. China) and water ad libitum.

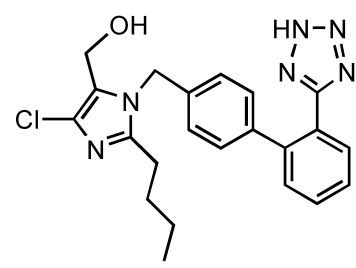

Losartan

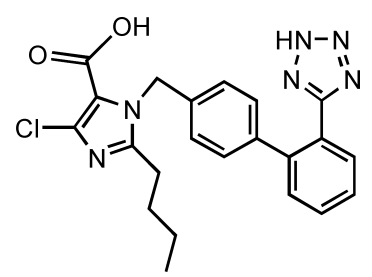

EXP3174
Fig. 2. Chemical Structures of Losartan and EXP3174 
The animal experiment followed the guidelines of the National Research Council.

Preparation of Curcumin The powder of Curcuma longa $\mathrm{L}$. $(5 \mathrm{~kg})$ was suspended and extracted with $75 \%$ ethanol $(5 \mathrm{~L})$ for 5 times by ultrasonic extraction, $2 \mathrm{~h}$ for each time. The filtrates were combined together and offered $500 \mathrm{~g}$ residue after concentration by a rotary vacuum evaporator. The crude extract was separated into three partition with a silica gel column eluted gradually with petroleum ether, mixture of petroleum ether and chloroform $(3: 1)$, and chloroform. The second partition (petroleum ether-chloroform 3:1) was subjected to a silica gel column with a gradient of petroleum ether in acetone. Four fractions were collected (volatile oil and compounds $\mathrm{CI}-\mathrm{CIII}$ ). Compound $\mathrm{CI}$ was identified as pure curcumin. The purity of curcumin was measured by HPLC analysis.

Pharmacokinetic Interactions between Curcumin and Losartan All rats were randomly divided into two groups, six rats in the control group and eight in the treatment group, and each group was consisting of either sex. Rats in the treatment group were gavaged with curcumin $(100 \mathrm{mg} / \mathrm{kg} / \mathrm{d}$, with $0.5 \%$ carboxymethyl cellulose as the vehicle) for seven consecutive days. Rats in the control group were gavaged with an equivalent volume of the vehicle for the same days. All animals were allowed free access to food and water, and were fasted overnight before pharmacokinetic experiment with free access to water. On day 7, half an hour after the regular administration, all of the rats were administered with $10 \mathrm{mg}$ / $\mathrm{kg}$ losartan dissolved in distilled water. Blood samples (approximate $0.1 \mathrm{~mL}$ ) were obtained from the orbital vein before dosing and at $0.25,0.5,1,2,3,4,6,8,12 \mathrm{~h}$ after dosing of losartan. The samples were put into heparinized tubes and plasma was isolated by centrifugation at $12000 \mathrm{rpm}$ for $10 \mathrm{~min}$. All plasma samples were stored at $-20^{\circ} \mathrm{C}$ until analysis.

Liquid Chromatography-Mass Spectrometry. Instruments and Chromatographic Conditions Liquid chromatography-tandem mass spectrometry assay for the quantitation of losartan and its oxidative metabolite EXP3174 was performed on an Agilent 1200 system equipped with an autosampler, a vacuum degasser unit, and a binary pump. The HPLC system was coupled to an Agilent G6410B triple-quadrupole mass spectrometer (Agilent Technologies, U.S.A.), equipped with electrospray ionization (ESI) run by Agilent Mass Hunter Workstation B.01.03. Chromatographic separation was performed using a ProntoSIL C18 column $(150 \mathrm{~mm} \times 3 \mathrm{~mm}, 3 \mu \mathrm{m}$, Bischoff, Germany). The mobile phase was water with $0.1 \%$ formic acid and acetonitrile $(40: 60, \mathrm{v} / \mathrm{v})$. The separation was performed under isocratic conditions with a constant flow rate of $0.4 \mathrm{~mL} / \mathrm{min}$, and the injection volume was $20 \mu \mathrm{L}$.

Standard Solutions and Calibrators Stock standard solutions of losartan $(103.2 \mu \mathrm{g} / \mathrm{mL})$, EXP3174 $(57.8 \mu \mathrm{g} / \mathrm{mL})$ were freshly prepared in acetonitrile. A series of working standard solutions were dissolved in acetonitrile and water $(1: 1$, $\mathrm{v} / \mathrm{v})$ to produce eight standard solutions ranging $1-2064 \mathrm{ng} /$ $\mathrm{mL}$ for losartan, and $0.6-1156 \mathrm{ng} / \mathrm{mL}$ for EXP3174, respectively. Matrix based calibrators were prepared by spiking $25 \mu \mathrm{L}$ of each standard solution to a final volume of $25 \mu \mathrm{L}$ plasma. Quality control samples were prepared at 2.6, 51.6 and $1858 \mathrm{ng} / \mathrm{mL}$ for losartan and 1.45, 28.9 and $1040 \mathrm{ng} / \mathrm{mL}$ for EXP3174. The working standard solution of irbesartan (internal standard (IS)) at $200 \mathrm{ng} / \mathrm{mL}$ was diluted with acetonitrile.
The inter-batch precision and accuracy were evaluated by processing a set of calibration and quality control samples in six separate batches. All solutions were stored at $-20^{\circ} \mathrm{C}$ until assay.

Sample Preparation and Analysis All frozen plasma samples were thawed at room temperature. For sample preparation, $25 \mu \mathrm{L}$ of plasma sample was added into a $1.5 \mathrm{~mL}$ centrifuge tube, followed by $25 \mu \mathrm{L}$ of acetonitrile-water solution (v/v, 50:50) and $25 \mu \mathrm{L}$ of the IS solution (irbesartan, 200 ng/ $\mathrm{mL}$ ). After vortex mixing for $30 \mathrm{~s}, 80 \mu \mathrm{L}$ of acetonitrile was added to the mixture to precipitate the plasma protein. After vortex mixing for $1 \mathrm{~min}$, the mixture was centrifuged at $11000 \mathrm{rpm}$ for $5 \mathrm{~min}$, the separated supernatant was analyzed immediately by LC-MS/MS system after preparation.

Pharmacokinetic Parameters The main pharmacokinetic parameters of losartan and EXP3174 were obtained by a noncompartmental model with the help of a computer designed program DAS (version 2.0, Anhui, China). Maximum concentration $\left(C_{\max }\right)$ and time to reach maximum concentration $\left(T_{\max }\right)$ were obtained directly from experimental observations. The area under the plasma concentration-time curve from zero to the last sampling time $\left(A U C_{0-t}\right)$ was calculated using the linear trapezoidal method.

Statistical Analysis All mean values were expressed as mean \pm S.D. The data for pharmacokinetics in rats were analyzed with DAS 2.0 and the pharmacokinetic parameters were compared using Student $t$-test. Differences were considered to be significant at a level of $p<0.05$.

\section{RESULTS}

Chromatographic and Mass Spectrometric Experimental Conditions The method of simultaneous determination of losartan and EXP3174 in rat plasma was developed and optimized. The compounds were ionized in the positive ion mode. The spray voltage was set at $4000 \mathrm{~V}$. Nitrogen was used as nebulizer gas and nebulizer pressure was set at 35 p.s.i. Desolvation gas (nitrogen) was heated to $300^{\circ} \mathrm{C}$ and delivered at a flow rate of $10 \mathrm{~L} / \mathrm{min}$. For collision-induced dissociation (CID), high purity nitrogen was used as collision gas at a pressure of $0.15 \mathrm{MPa}$. Quantification was performed using multiple reaction monitoring (MRM) mode at $m / z \quad 423.1 \rightarrow 207.1$ for LOS, $m / z 437.1 \rightarrow 207.1$ for EXP3174 and $m / z \quad 429.1 \rightarrow 195.1$ for irbesartan (IS), respectively (Fig. 3). Retention times for losartan, EXP3174 and irbesartan were at 2.94, 2.98 and $3.85 \mathrm{~min}$, respectively, with a total run time of $4.0 \mathrm{~min}$. The optimized collision energies of 20,24 and $25 \mathrm{eV}$ were used for LOS, EXP3174 and irbesartan, respectively. The dwell time was set at $200 \mathrm{~ms}$ for each analyte.

Method Validation. Selectivity and Matrix Effects No endogenous interference was observed at retention times of losartan, EXP3174 and IS in this method. Analytical signals from blank rat plasma were compared with those obtained from the rat plasma spiked with losartan and EXP3174 at the LLOQ and the IS. The representative chromatograms of the plasma samples are shown in Fig. 3. In addition, chromatograms obtained from rat plasma samples at $2 \mathrm{~h}$ after dosing with $10 \mathrm{mg} / \mathrm{kg}$ losartan are illustrated in Fig. 3.

Three replicate analyses of samples at 2.6 and $1860 \mathrm{ng} /$ $\mathrm{mL}$ in plasma and in acetonitrile were performed. The ratios of the absolute peak areas at the same concentrations were 


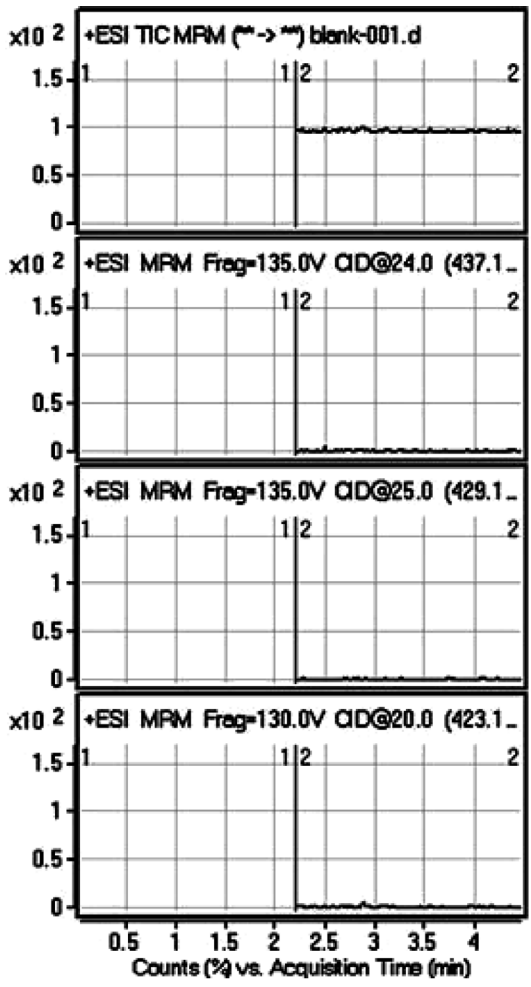

(a)

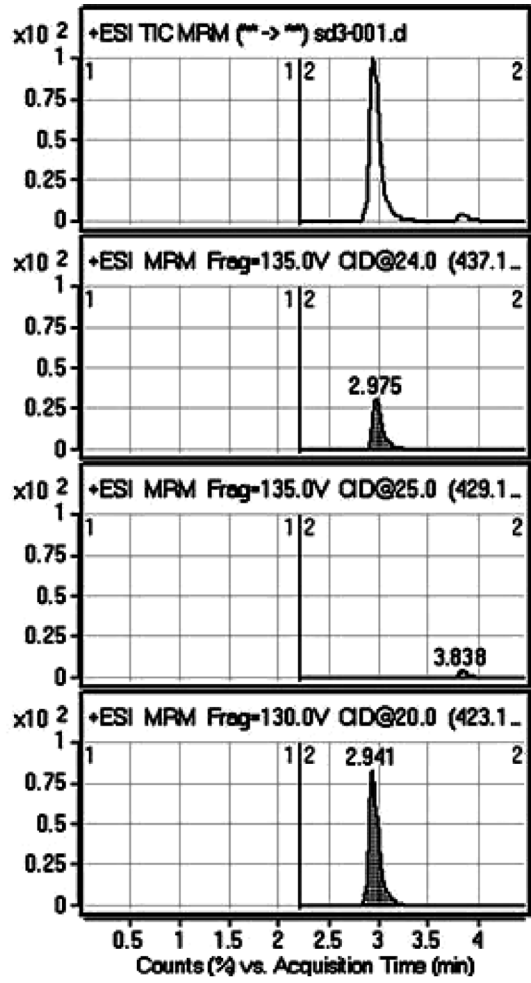

(b)

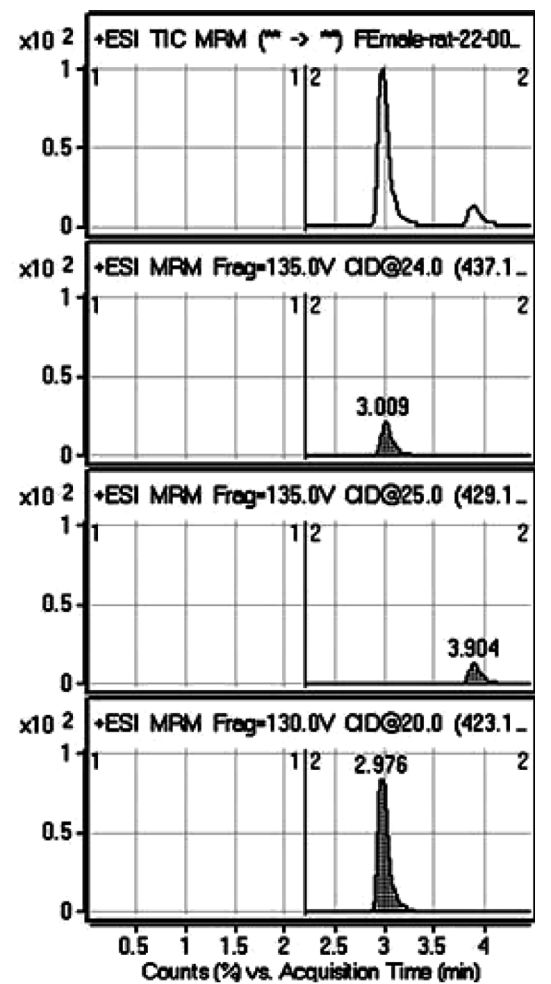

(c)

Fig. 3. Chromatograms of Rat Plasma

(a) Blank, (b) blank spiked with losartan and EXP3174 at LLOQ and IS, (c) sample at $2 \mathrm{~h}$ after dosing with $10 \mathrm{mg}$ losartan.

Table 1. Precision and Accuracy of the Method for Determining Losartan and EXP3174 Concentrations in Rats Plasma

\begin{tabular}{|c|c|c|c|c|c|c|c|}
\hline \multirow{2}{*}{ Analyte } & \multirow{2}{*}{$\begin{array}{l}\text { Concentration } \\
\text { added }(\mathrm{ng} / \mathrm{mL})\end{array}$} & \multicolumn{3}{|c|}{ Intra-batch } & \multicolumn{3}{|c|}{ Inter-batch } \\
\hline & & $\begin{array}{l}\text { Concentration measured } \\
(\text { mean } \pm \text { S.D.; ng/mL) }\end{array}$ & CV (\%) & RE (\%) & $\begin{array}{l}\text { Concentration measured } \\
(\text { mean } \pm \text { S.D.; ng } / \mathrm{mL})\end{array}$ & CV (\%) & RE (\%) \\
\hline \multirow{3}{*}{ Losartan } & 2.58 & $2.63 \pm 0.09$ & 3.42 & 1.94 & $2.54 \pm 0.12$ & 4.72 & -1.55 \\
\hline & 51.6 & $52.5 \pm 1.4$ & 2.67 & 1.74 & $52.2 \pm 1.39$ & 2.66 & 1.09 \\
\hline & 1860 & $1780 \pm 22.9$ & 1.29 & -4.43 & $1770 \pm 24.4$ & 1.38 & -4.74 \\
\hline \multirow{3}{*}{ EXP3174 } & 1.45 & $1.40 \pm 0.12$ & 8.57 & -3.45 & $1.48 \pm 0.11$ & 7.43 & 2.07 \\
\hline & 28.9 & $30.1 \pm 0.67$ & 2.22 & 4.26 & $30.0 \pm 0.59$ & 1.97 & 3.77 \\
\hline & 1040 & $1070 \pm 14.6$ & 1.37 & 2.67 & $1050 \pm 22.9$ & 2.18 & 1.00 \\
\hline
\end{tabular}

$\mathrm{CV}(\%)=$ S.D. of measured value/mean measured value $\times 100 . \mathrm{RE}(\%)=($ measured concentration - nominal concentration $) /$ nominal concentration .

within the range $0.95-1.09$ and $0.99-1.28$ for losartan and EXP3174, respectively. These results showed that matrix effects are negligible and can be ignored.

Calibration and Linearity The calibration curve was linear over the concentration range $1.03-2060 \mathrm{ng} / \mathrm{mL}$ for losartan and $0.578-1160 \mathrm{ng} / \mathrm{mL}$ for EXP3174. The best linear fit and least-squares residual for the calibration curve were achieved with a $1 / x^{2}$ weighing factor. The mean correlation coefficient $(r)$ of the weighted calibration curve generated during the validation was $\geq 0.9985$ for losartan and EXP3174.

Precision and Accuracy The intra- and inter-batch precision and accuracy of the method are illustrated in Table 1. Six sets of quality control samples (low, medium and high concentration) were analyzed with calibration samples in one batch.

Recovery Recoveries of the analytes and IS were high and consistent. The recoveries of losartan and EXP3174 were $95.7 \%$ and $83.3 \%$, respectively.

Stability Stock solutions were established and tested at room temperature for 0 and $24 \mathrm{~h}$, and under refrigeration $\left(-20^{\circ} \mathrm{C}\right)$ for $24 \mathrm{~d}$. Stabilities of the analytes and IS in rat plasma were assessed for $2 \mathrm{~h}, 24 \mathrm{~h}$. The freeze-thaw stabilities were measured after three freeze-thaw cycles $\left(-20^{\circ} \mathrm{C}\right.$ to room temperature) on consecutive days. All the stabilities were conducted at two QC concentration levels (low and high). No significant change $(p<0.05)$ of the analytes concentration was observed.

Pharmacokinetics of Losartan and EXP3174 The plasma concentration-time profiles of losartan after an oral dose of $10 \mathrm{mg} / \mathrm{kg}$ to rats,with or without $7 \mathrm{~d}$ curcumin,are shown in Fig. 4. The corresponding pharmacokinetic parameters are 
listed in Table 2. Compared with the control group, rats prior exposure to curcumin had significantly increased in $A U C_{0-t}$ and $C_{\max }$ of the oral losartan. Administration of $10 \mathrm{mg} / \mathrm{kg}$ losartan in the treatment group resulted in a marked increase in the $A U C_{0-t}$ and $C_{\max }$ from $2080 \pm 837$ to $3460 \pm 1350 \mu \mathrm{g} / \mathrm{L} \cdot \mathrm{h}$ and $475 \pm 63.1$ to $1660 \pm 892 \mu \mathrm{g} / \mathrm{L}$, respectively. An approximate 1.7-fold increase of the $A U C_{0-t}$ and 3.5-fold increase of the $C_{\max }$ in treatment group.

It can be seen in Fig. 5 and Table 2,compared with the control group,the $A U C_{0-t}$ and $C_{\max }$ of EXP3174 of treatment group were significantly increased from $766 \pm 416$ to $1460 \pm 818 \mu \mathrm{g} / \mathrm{L} \cdot \mathrm{h}$ and $108 \pm 61.1$ to $341 \pm 187 \mu \mathrm{g} / \mathrm{L}$, respectively. $T_{\max }$ of EXP3174 of the control group was nonsignificantly $78 \%$ higher than that of group pre-treated with curcumin $(3.33 \pm 2.34$ to

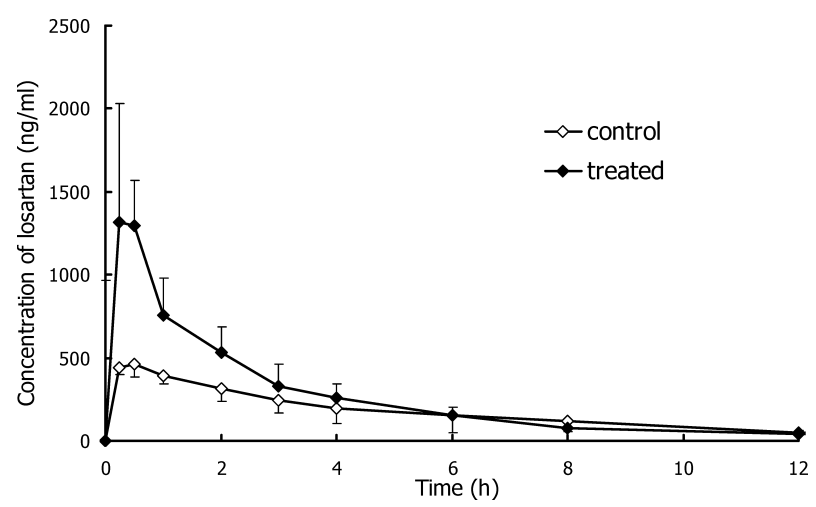

Fig. 4. Mean Plasma Concentration-Time Curves of Losartan in Rats after Oral Administration of Losartan in Single Dose and after $7 \mathrm{~d}$ Repeated Administration of Curcumin

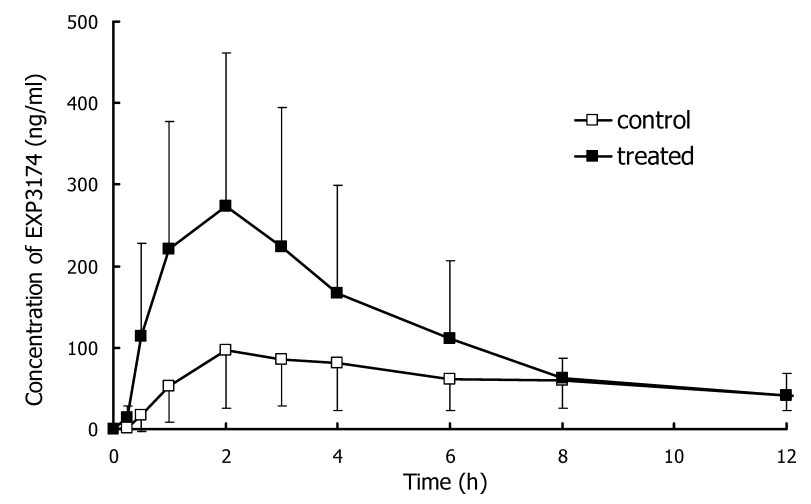

Fig. 5. Mean Plasma Concentration-Time Curves of EXP3174 in Rats after Oral Administration of Losartan in Single Dose and after $7 \mathrm{~d}$ Repeated Administration of Curcumin
$1.88 \pm 0.64 \mathrm{~h})$

\section{DISCUSSION}

Change of a drug delivery to its site of action may result in pharmacokinetic interaction, which probablely caused by minor alteration of any step of absorption, distribution, metabolism, or elimination. ${ }^{18)}$ Losartan has been shown to take effect in drug interactions mostly owing to its metabolism. ${ }^{19)}$ Present study was carried out in Wistar rats to investigate effect of pre-treatment with curcumin on the pharmacokinetic of losartan following single oral administration. The reason we chose rats as animal model for the interaction investigation is its similarity to humans on the pharmacodynamic and pharmacokinetic actions of losartan.

The pharmacokinetic of losartan and EXP3174 after a single oral dose were analyzed in rats with or without prior repeat doses of curcumin for seven days. Losartan is converted to an active metabolite, EXP3174 (about 14\%), ${ }^{20)}$ which is the main activity metabolite of losartan. EXP3174 has stronger pharmacological effects than the parent compound, ${ }^{21)}$ and it mediates the mainly pharmacological influences of losartan. Thus, in present investigation, the pharmacokinetic interaction were studied by measuring the concentration of losartan and EXP3174, respectively.

The dosages of curcumin and losartan used in study were based on similar researches, ${ }^{22,23)}$ respectively. The pharmacokinetic behaviors of losartan and EXP3174 were described using non-compartment model. Our findings revealed that coadministration with curcumin may result in higher concentrations of losartan and EXP3174 in plasma. In the present study, the pharmacokinetic profiles of losartan and EXP3174 were significantly altered in rats treated with curcumin compared with the control. The $A U C_{0-t} \mathrm{~s}$ of losartan and EXP3174 of the group pre-treatment with curcumin were about $70 \%$ and $90 \%$, respectively, greater than those of losartan administration alone. The $C_{\max }$ s of losartan and EXP3174 were significantly increased by curcumin to 3.5 -fold and to 3.2-fold of their control values, respectively.

This pharmacokinetic modulation of losartan might be attributed to changes in the absorption and metabolism. Losartan is a drug transporter protein (P-gp) substrate, ${ }^{24)}$ and undergoes extensive metabolism involving both oxidation and glucuronidation. The oxidation metabolism of losartan in vivo is catalyzed by cytochrome P450 (CYP) 2C and $3 A^{25)}$ Moreover, losartan glucuronidated mainly by UDPglucuronosyltransferases (UGTs) $1 \mathrm{~A} 1$ and 2B7. Thus, the modulation of P-gp or CYPs or UGTs may affect the pharma-

Table 2. The Main Pharmacokinetic Parameters of Losartan and EXP3174 at Losartan Alone and after Repeated Administration of Curcumin

\begin{tabular}{|c|c|c|c|c|}
\hline \multirow{2}{*}{ Analyte } & \multirow{2}{*}{ Parameter } & \multirow{2}{*}{ Unit } & \multicolumn{2}{|c|}{ Value (mean \pm S.D.) } \\
\hline & & & Control & Treated \\
\hline \multirow{3}{*}{ Losartan } & $A U C_{(0-t)}$ & $\mu \mathrm{g} / \mathrm{L} \cdot \mathrm{h}$ & $2080 \pm 837$ & $3460 \pm 1350$ \\
\hline & $T_{\max }$ & $\mathrm{h}$ & $0.38 \pm 0.14$ & $0.38 \pm 0.13$ \\
\hline & $C_{\max }$ & $\mu \mathrm{g} / \mathrm{L}$ & $475 \pm 63.1$ & $1660 \pm 892 * *$ \\
\hline \multirow{3}{*}{ EXP3174 } & $A U C_{(0-t)}$ & $\mu \mathrm{g} / \mathrm{L} \cdot \mathrm{h}$ & $766 \pm 416$ & $1460 \pm 818^{*}$ \\
\hline & $T_{\max }$ & $\mathrm{h}$ & $3.33 \pm 2.34$ & $1.88 \pm 0.64$ \\
\hline & $C_{\max }$ & $\mu \mathrm{g} / \mathrm{L}$ & $108 \pm 61.1$ & $341 \pm 187 * *$ \\
\hline
\end{tabular}

*Comparing to control group, $p$ value $<0.05$; ** Comparing to control group, $p$ value $<0.01$. 
cokinetic profile of losartan.

Curcumin has been demonstrated to down regulate the P-gp levels in rat, ${ }^{16,26)}$ and the cell-based assay using rhodamine 123 indicated that curcumin significantly inhibited the activity of P-gp with a decrease in P-gp protein and multidrug resistance gene MDR1 mRNA levels. Referring to the studies, ${ }^{22,27)}$ pretreatment with curcumin could alter the oral bioavailability of docetaxel and norfloxacin, which are substrates of P-gp. Therefore, the improved absorption of losartan caused by inhibition of P-gp is likely to result in higher increased $A U C$ and $C_{\max }$. Furthermore, the ability of curcumin to suppress 10 members of UGTs including UGT1A1 and $2 B 7^{28)}$ might have delayed the glucuronidation process of losartan.

Previous reports have proved that EXP3174 detected in rats is most likely of hepatic origin. ${ }^{25,29)}$ However, curcumin attenuated the CYP3A level in the small intestine but not in the liver. ${ }^{14)}$ Therefore, it can be hypothesized that the systematic exposure of curcumin is inadequate to inhibit the activity of CYPs in liver, and do little effect on the metabolism of losartan.

The further elimination of EXP3174 also depends on UGTs. $^{30)}$ In the investigation, the plasma concentration of EXP3174 is higher in treatment group than that in control one. Firstly, the increase of losartan result from the above reason may produce more volume of metabolite. Secondly, the inhibition of curcumin on UGTs contribute to the less elimination of EXP3174.

In the present study the $t_{1 / 2}$ of losartan and EXP3174 were not significantly changed, which suggested that the increased plasma concentration observed in the study may be mainly attributable to the improved absorption of losartan. The inhibition of P-gp by curcumin is the main pathway affecting the pharmacokinetics of losartan and EXP3174 in rat pretreated with curcumin, while inhibition of UGTs and CYPs play a minor role .

The increased plasma levels of losartan and EXP3174 indicates that prior administration of curcumin may result in strong pharmacological actions such as blood pressure decrease, and lead to adverse drug reaction. On the one hand, we should be kept in mind that losartan with curcumin may cause herb-drug interaction. On the other hand, from a practical point of view, pre-treatment with curcumin can be developed as enhancer agent of losartan to reduce the drug dose on the base of appropriate dose titration studies.

In addition, a highly sensitive and specific LC/MS/MS method for the quantitation of losartan and EXP3174 has been developed, in the present study. The method has been validated with a routine sensitivity limit of $1.03 \mathrm{ng} / \mathrm{mL}$ in $25 \mu \mathrm{L}$ rat plasma. Using this method, pharmacokinetics of losartan and EXP3174 following an administration of losartan $10 \mathrm{mg} /$ $\mathrm{kg}$ was investigated in rats. The plasma levels of the two drugs have been found at lower level and shorter duration than previously reported. ${ }^{31)}$ The developed method could be efficiently used in losartan therapeutic drug monitoring in clinical situation.

In conclusion, the pharmacokinetic profile of losartan affected by curcumin was revealed in rat, which may help to guide the clinical administration of losartan in hypertension patients with further investigation in clinical trials. Furthermore, the developed method could be used in losartan therapeutic drug monitoring in clinical settings.
Acknowledgement The study was supported by The National Natural Science Foundation of China (No. 31101241).

\section{REFERENCES}

1) Kamper M, Tsimpoukidi O, Chatzigeorgiou A, Lymberi M, Kamper EF. The antioxidant effect of angiotensin II receptor blocker, losartan, in streptozotocin-induced diabetic rats. Transl. Res., 156, 26-36 (2010).

2) Argani H, Ghorbanihaghjo A, Aghaeishahsavari M, Noroozianavval M, Rashtchizadeh N, Veisi P, Safa J, Abediazar S. Effects of losartan and enalapril on high-sensitivity C-reactive protein and total antioxidant in renal transplant recipients with Renin-Angiotensin system polymorphisms. Transplant. Proc., 40, 16-21 (2008).

3) Yao EH, Fukuda N, Matsumoto T, Kobayashi N, Katakawa M, Yamamoto C, Tsunemi A, Suzuki R, Ueno T, Matsumoto K. Losartan improves the impaired function of endothelial progenitor cells in hypertension via an antioxidant effect. Hypertens. Res., 30, 1119-1128 (2007).

4) Liptáková A, Ulicná O, Duracková Z, Bozek P, Vancová O. Effect of losartan on antioxidant status in rats with diabetes mellitus. Ceska Slov. Farm., 50, 193-196 (2001).

5) García G, Rodríguez-Puyol M, Alajarín R, Serrano I, SánchezAlonso P, Griera M, Vaquero JJ, Rodríguez-Puyol D, Alvarez-Builla J, Díez-Marqués ML. Losartan-antioxidant hybrids: novel molecules for the prevention of hypertension-induced cardiovascular damage. J. Med. Chem., 52, 7220-7227 (2009).

6) Chan MM. Inhibition of tumor necrosis factor by curcumin, a phytochemical. Biochem. Pharmacol., 49, 1551-1556 (1995).

7) Zhong F, Chen H, Han L, Jin Y, Wang W. Curcumin attenuates lipopolysaccharide-induced renal inflammation. Biol. Pharm. Bull., 34, 226-232 (2011).

8) Brouet I, Ohshima H. Curcumin, an anti-tumour promoter and anti-inflammatory agent, inhibits induction of nitric oxide synthase in activated macrophages. Biochem. Biophys. Res. Commun., 206, $533-540$ (1995).

9) Guangwei X, Rongzhu L, Wenrong X, Suhua W, Xiaowu Z, Shizhong W, Ye Z, Aschner M, Kulkarni SK, Bishnoi M. Curcumin pretreatment protects against acute acrylonitrile-induced oxidative damage in rats. Toxicology, 267, 140-146 (2010).

10) Surveswaran S, Cai Y, Corke H, Sun M. Systematic evaluation of natural phenolic antioxidants from 133 Indian medicinal plants. Food Chem., 102, 938-953 (2007).

11) Sharma RA, Euden SA, Platton SL, Cooke DN, Shafayat A, Hewitt HR, Marczylo TH, Morgan B, Hemingway D, Plummer SM, Pirmohamed M, Gescher AJ, Steward WP. Phase I clinical trial of oral curcumin: biomarkers of systemic activity and compliance. Clin. Cancer Res., 10, 6847-6854 (2004).

12) Cheng AL, Hsu CH, Lin JK, Hsu MM, Ho YF, Shen TS, Ko JY, Lin JT, Lin BR, Ming-Shiang W, Yu HS, Jee SH, Chen GS, Chen TM, Chen CA, Lai MK, Pu YS, Pan MH, Wang YJ, Tsai CC, Hsieh CY. Phase I clinical trial of curcumin, a chemopreventive agent, in patients with high-risk or pre-malignant lesions. Anticancer Res., 21(4B), 2895-2900 (2001).

13) Dhillon N, Aggarwal BB, Newman RA, Wolff RA, Kunnumakkara AB, Abbruzzese JL, Ng CS, Badmaev V, Kurzrock R. Phase II trial of curcumin in patients with advanced pancreatic cancer. Clin. Cancer Res., 14, 4491-4499 (2008).

14) Zhang W, Tan TM, Lim LY. Impact of curcumin-induced changes in P-glycoprotein and CYP3A expression on the pharmacokinetics of peroral celiprolol and midazolam in rats. Drug Metab. Dispos., 35, 110-115 (2007).

15) Aguilar F, Dusemund B, Galtier P, Gilbert J, Gott DM, Grilli S, Gürtler R, König J, Lambré C, Larsen J-C, Leblanc J-C, Mortensen A, Parent-Massin D, Pratt I, Rietjens IMCM, Stankovic I, Tobback P, Verguieva T, Woutersen RA. Re-evaluation of curcumin (E 100) 
as a food additive. EFSA Journal, 8, 1679 (2010).

16) Yao QH, Wang DQ, Cui CC, Yuan ZY, Chen SB, Yao XW, Wang JK, Lian JF. Curcumin ameliorates left ventricular function in rabbits with pressure overload: inhibition of the remodeling of the left ventricular collagen network associated with suppression of myocardial tumor necrosis factor-alpha and matrix metalloproteinase-2 expression. Biol. Pharm. Bull., 27, 198-202 (2004).

17) Ramaswami G, Chai H, Yao Q, Lin PH, Lumsden AB, Chen C. Curcumin blocks homocysteine-induced endothelial dysfunction in porcine coronary arteries. J. Vasc. Surg., 40, 1216-1222 (2004)

18) Faulx MD, Francis GS. Adverse drug reactions in patients with cardiovascular disease. Curr. Probl. Cardiol., 33, 703-768 (2008).

19) Song JC, White CM. Pharmacologic, pharmacokinetic, and therapeutic differences among angiotensin II receptor antagonists. Pharmacotherapy, 20, 130-139 (2000).

20) McIntyre M, Caffe SE, Michalak RA, Reid JL. Losartan, an orally active angiotensin (AT1) receptor antagonist: a review of its efficacy and safety in essential hypertension. Pharmacol. Ther., $\mathbf{7 4}$ 181-194 (1997).

21) Suzuki J, Ohta H, Hanada K, Kawai N, Ikeda T, Nakao M, Ikemoto F, Nishikibe M. Acute effects of E-3174, a human active metabolite of losartan, on the cardiovascular system in tachycardia-induced canine heart failure. Hypertens. Res., 24, 65-74 (2001).

22) Yan YD, Kim DH, Sung JH, Yong CS, Choi HG. Enhanced oral bioavailability of docetaxel in rats by four consecutive days of pretreatment with curcumin. Int. J. Pharm., 399, 116-120 (2010).

23) Kobayashi M, Takagi M, Fukumoto K, Kato R, Tanaka K, Ueno K. The effect of bucolome, a CYP2C9 inhibitor, on the pharmacokinetics of losartan. Drug Metab. Pharmacokinet., 23, 115-119 (2008).

24) Díez J. Review of the molecular pharmacology of Losartan and its possible relevance to stroke prevention in patients with hyperten- sion. Clin. Ther., 28, 832-848 (2006).

25) Stearns RA, Chakravarty PK, Chen R, Chiu SH. Biotransformation of losartan to its active carboxylic acid metabolite in human liver microsomes. Role of cytochrome P4502C and 3A subfamily members. Drug Metab. Dispos., 23, 207-215 (1995).

26) Hou XL, Takahashi K, Tanaka K, Tougou K, Qiu F, Komatsu K, Takahashi K, Azuma J. Curcuma drugs and curcumin regulate the expression and function of P-gp in Caco-2 cells in completely opposite ways. Int. J. Pharm., 358, 224-229 (2008).

27) Pavithra BH, Prakash N, Jayakumar K. Modification of pharmacokinetics of norfloxacin following oral administration of curcumin in rabbits. J. Vet. Sci., 10, 293-297 (2009).

28) Basu NK, Kole L, Kubota S, Owens IS. Human UDP glucuronosyltransferases show atypical metabolism of mycophenolic acid and inhibition by curcumin. Drug Metab. Dispos., 32 , $768-773$ (2004).

29) Krieter PA, Colletti AE, Miller RR, Stearns RA. Absorption and glucuronidation of the angiotensin II receptor antagonist losartan by the rat intestine. J. Pharmacol. Exp. Ther., 273, 816-822 (1995).

30) Klein TE, Chang JT, Cho MK, Easton KL, Fergerson R, Hewett M, Lin Z, Liu Y, Liu S, Oliver DE, Rubin DL, Shafa F, Stuart JM, Altman RB. Integrating genotype and phenotype information: an overview of the PharmGKB project. Pharmacogenetics Research Network and Knowledge Base. Pharmacogenomics J., 1, 167-170 (2001).

31) Iwasa T, Takano T, Hara K, Kamei T. Method for the simultaneous determination of losartan and its major metabolite, EXP-3174, in human plasma by liquid chromatography-electrospray ionization tandem mass spectrometry. J. Chromatogr. B Biomed. Sci. Appl., 734, 325-330 (1999). 